\title{
Performance Analysis of Aodv, Dsdv, Dsr and Lar Routing Protocols In Manet- A Review
}

\author{
Ruchi Aggarwal ${ }^{1}$, Amanpreet Kaur $^{2}$ \\ Department of Computer Sc. \& Engg. , Chandigarh University, Gharuan, Punjab, India
}

\begin{abstract}
Mobile ad Hoc network is a collection of mobile nodes that communicate with each other using wireless links. A routing protocol is used to discover routes between nodes in order to facilitate communication within the network area. An ad Hoc network routing protocol helps to maintain correct and efficient route establishment between nodes so that messages may be delivered timely. This review paper describes the characteristics of ad Hoc routing protocols AODV, DSDV, DSR and LAR. And then provides a comparison and discussion of their respective merits and drawbacks.
\end{abstract}

Keywords: Manet, Aodv, Dsdv, Dsr, Lar

\section{INTRODUCTION}

A mobile ad Hoc network (MANET) consists of a collection of mobile nodes which dynamically forms a temporary network. The use of wireless ad Hoc network becomes very popular. In Mobile Ad-Hoc network nodes are free to move randomly, because of which topology of the network keeps on changing rapidly and may be unpredictable. The main aim of MANET is to provide communication capabilities to areas where limited or no predetermined communication infrastructures exist.

MANETs have several salient characteristics:

1) Dynamic network topologies

2) Bandwidth constrained, variable capacity links

3) Energy-constrained operation

4) Nodes can perform the roles of both hosts and routers

5) Frequent routing updates

6) Limited physical security

Some MANET usage areas are Military scenarios, Sensor networks, Rescue operations, Students on campus, free internet connection sharing, and conferences.

MANET uses multi-hop routing to provide network connectivity. The goal of routing protocols are- Find short routes, Decrease routing-related overhead and find - stable routes.

\section{AD HOC ROUTING PROTOCOLS}

Routing protocols as shown in Figure 1 may generally be categorized as:

- Table-driven

- Source-initiated (demand-driven)

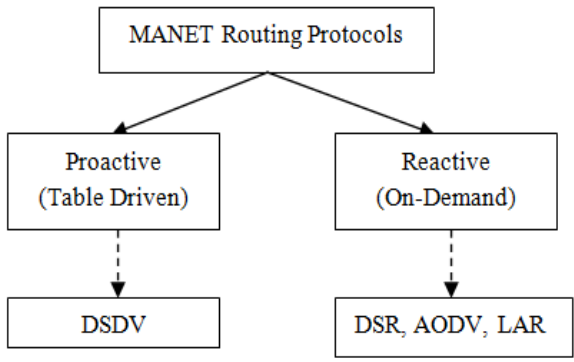

Fig 1. Classification of Routing Protocols

A.

Table-Driven Routing Protocols 
In Proactive routing protocol, each mobile node maintains a routing table. Each node contains the following information:

1. How many hops are required to reach the destination node

2. A new sequence number marked by the destination

3. The destination address

Such routing information is available immediately, when a route to a destination is needed. Proactive protocols continuously maintains and updates the routing table within the network so that when we are required to forward, the packet route is already known and immediately ready for use. So there is not any time delay because there is no time spent in route discovery process. So a shortest path can be find without any time delay. However these protocols are not suitable for very dense ad-Hoc networks because in that condition problem of high traffic may arise.

The main disadvantages of such algorithms are high latency time in route finding and excessive flooding can lead to network clogging.

Examples of the proactive protocols are - DSDV (Destination-Sequenced Distance-Vector), Wireless Routing Protocol (WRP), Hierarchical State Routing protocol and Optimized Link State Routing (OLSR).

\section{B. Reactive Routing Protocols}

Reactive Routing Protocols are also called on demand routing. It is more efficient than proactive routing. The main idea behind this type of routing is to find a route between a source and destination whenever that route is needed which helps to avoid routing overhead, whereas in proactive protocols we were maintaining all routes without knowing its state of use. So in reactive protocols we do not need to maintain the routes which are not being used currently. This type of routing is on demand. On demand routing protocols avoids the cost of maintaining routes that are not being used.

Example: Ad-Hoc On Demand Distance Vector (AODV), and Dynamic Source Routing (DSR), Temporary Ordered Routing Algorithm (TORA), Location Aided Routing (LAR) etc.

\section{DESTINATION-SEQUENCED DISTANCE-VECTOR ROUTING (DSDV)}

The Destination- Sequenced Distance-Vector Routing protocol (DSDV) described is a table-driven algorithm based on the classical Bellman-Ford routing mechanism. The improvements made to the BellmanFord algorithm include freedom from loops in routing tables. Every mobile node in the network maintains a routing table which includes all of the possible destinations within the network and the number of hops to each destination. Sequence number is assigned to each entry by the destination node. Nodes are able to distinguish unused routes from new ones with the help of sequence number which avoids the formation of loops. Routing table updates are periodically transmitted throughout the network to maintain table consistency.

New route broadcasts contain the destination address, the number of hops to reach the destination, the sequence number of the information received regarding the destination, as well as a new sequence number unique to the broadcast [2]. Route which has the latest sequence number is always used. If we have two updates with the same sequence number, the route with the smaller metric is used in order to shorten the path. Mobiles also keep track of the settling time of routes, or the weighted average time that routes to a destination will fluctuate before the route with the best metric is received [2]. By delaying the broadcast of a routing update by the length of the settling time, mobiles can reduce network traffic and optimize routes by eliminating those broadcasts that would occur if a better route was discovered in the very near future.

\section{DYNAMIC SOURCE ROUTING PROTOCOL (DSR)}

DSR is an on demand source routing protocol. This protocols work on two main mechanisms i.e. "Route Discovery" and "Route Maintenance". Route Maintenance ensures that the communication path remains optimum and loop-free according the change in network conditions, even if this requires altering the route during a transmission [3]. As shown in Fig 2a) Route discovery process is used to dynamically determine a route to destination which is not known.

In Route discovery the data packets are flooded in the network with route request (RREQ) packets. Every neighbor node receives RREQ packets and this flooding process continues by retransmissions of RREQ packets, until it gets destination or its route cache consists a route for destination. The node which contains the route to destination replies to the RREQ with a route reply RREP packet as shown in Fig 2b) that is routed back to source node. If any connection on a source route is wrecked, a route error (RERR) packet is notified to the source node. 


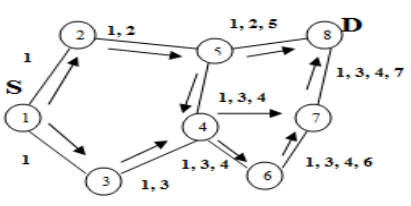

a) Route Discovery

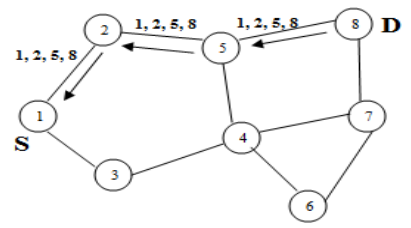

b) Route Reply

Fig 2. DSR Route Discovery Process

\section{ADHOC ON DEMAND DISTANCE VECTOR ROUTING (AODV)}

The Ad Hoc On-Demand Distance Vector routing protocol (AODV) is an improvement of the Destination-Sequenced Distance Vector routing protocol (DSDV). DSDV has its efficiency in creating smaller ad-Hoc networks. Since it requires periodic advertisement and global dissemination of connectivity information for correct operation, it leads to frequent system-wide broadcasts. Therefore the size of DSDV ad-Hoc networks is strongly limited. When using DSDV, every mobile node also needs to maintain a complete list of routes for each destination within the mobile network. AODV protocol is a distance vector routing protocol that operates on-demand. When a node wants to communicate with other node only then routes are set up. The nodes which lie on the path between the two end nodes only keep information about the route. When a source node wants to communicate with a destination node it initiates route discovery process as shown in figure $3 a$ ). Route discovery works by flooding the network with route request (RREQ) packets.

When a node receives the RREQ it checks its routing table to see if it is the destination or is it contains a fresh route to the destination. If it has the route to the destination, it sends a route reply (RREP) message back to the source as shown in figure 3b), else it rebroadcasts the RREP. Each node keeps track of its neighbours. This is performed by regularly exchanging HELLO messages. If a route in the ad Hoc network is broken then some node along this route will detect that the next hop router is unreachable. If this node has any active neighbours that depend on the broken link, it will propagate route error (RERR) messages to all of them. A node that receives a RERR will do the same check and if necessary propagate the RERR further in order to inform all nodes concerned.

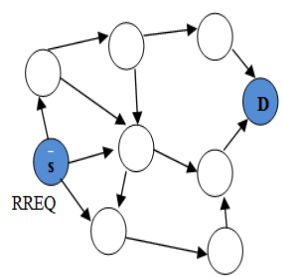

a) Source $\mathrm{S}$ initiates the path discovery process

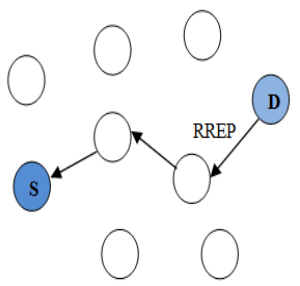

b) RREP packet is sent back to the source

Fig 3. AODV Path Discovery Process 
The advantage of AODV is that it tries to minimize the number of required broadcasts. It creates the routes on a on-demand basis, as opposed to maintain a complete list of routes for each destination.

\section{LOCATION-AIDED ROUTING (LAR)}

The goal of Location-Aided Routing (LAR) is to reduce the routing overhead by the use of location information. Location information is used to restrict the flooding to a certain area. In Location Aided Routing protocol Global Positioning System (GPS) is used to achieve the physical location of node. GPS is not capable of determining a node's exact position, it can offer accuracies within only a few meters. LAR consists of 2 zones: Expected zone and Request zone.

Expected Zone When a source node $\mathrm{S}$ wants to send a packet to some destination node D and needs to find a route, firstly it try to make a reasonable guess where $\mathrm{D}$ could be located. Let's assume node $\mathrm{S}$ knows that at time $t_{0} D$ 's position was $P$, and the current time is $t_{1}$. If $\mathrm{D}$ travelled with an average speed $\mathrm{v}$, the source node $\mathrm{S}$ expects $\mathrm{D}$ to be in a circle around the old position $\mathrm{P}$ with a radius $\mathrm{v}\left(\mathrm{t}_{1}-\mathrm{t}_{0}\right)$ as shown in figure 4 . The expected zone is only an estimate by $S$ to determine possible locations of $D$. If $D$ travelled with a higher speed than $S$ expected, the destination node may be outside the expected zone at time $t_{1}$. It is not be possible to estimate an expected zone, if the source node is not aware about the position of $\mathrm{D}$ at time $\mathrm{t}_{0}$. $\mathrm{D}$ could be anywhere. In this case, the entire network is selected as the expected zone and the routing algorithm reduces to a simple flooding.

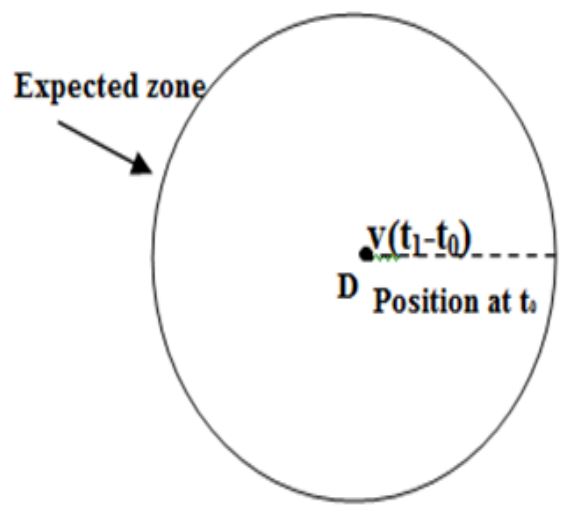

Fig 4. LAR Expected zone

Request Zone $\mathrm{S}$ is our source node that wants to send a packet to destination node D. Request zone defines the zone from where a route request is forwarded. Only an intermediate node which belongs to the route request will forward a route request packet. The request zone should contain the expected zone to reach destination node $\mathrm{D}$. The request zone may also include further regions:

- $\quad$ Both nodes must be present in the request zone, to create a path from $\mathrm{S}$ to $\mathrm{D}$ as shown in figure 5(a)

- If source $\mathrm{S}$ is not present in the expected zone of $\mathrm{D}$, under these kind of circumstances there may be no route from $S$ to $D$, even if both nodes are present in the requested zone as shown in figure 5(b). For instance, nodes that are near, but outside the request zone are needed to propagate the packet. Thus, after some timeout period, the request zone will be expanded, if no route is found from $S$ to $D$, and $S$ will initiate a new route discovery process figure $5(\mathrm{c})$. In this case, multiple route discoveries are needed because the route determination process will take longer.

LAR defines two different types of request zones.LAR uses two schemes: LAR Scheme 1 and LAR Scheme 2.
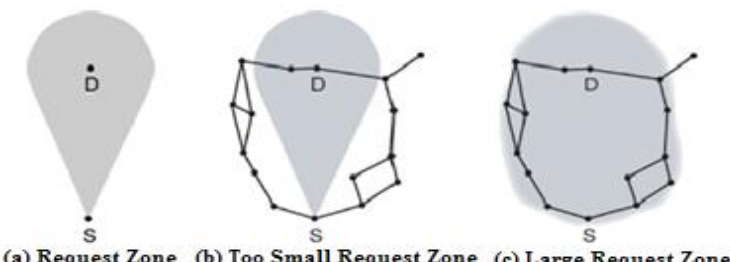

Fig 5. LAR - Different Request Zones 
LAR Scheme 1 (LAR1) The request zone of LAR1 is a rectangular geographic area. Remember: If source node $\mathrm{S}$ knows a previous location $\mathrm{P}$ of destination node $\mathrm{D}$ at time $\mathrm{t}_{0}$, and average speed $\mathrm{v}$ and the current time $t_{1}$, then the expected zone at time $t_{1}$ is a circle around $P$ with radius $r=v\left(t_{1}-t_{0}\right)$. The smallest possible rectangle is defined as the Request zone that includes source node $\mathrm{S}$ and the circle is defined as the expected zone as shown in figure 6 .

The sides of the rectangle be parallel to the $\mathrm{x}$ and $\mathrm{y}$ axes.

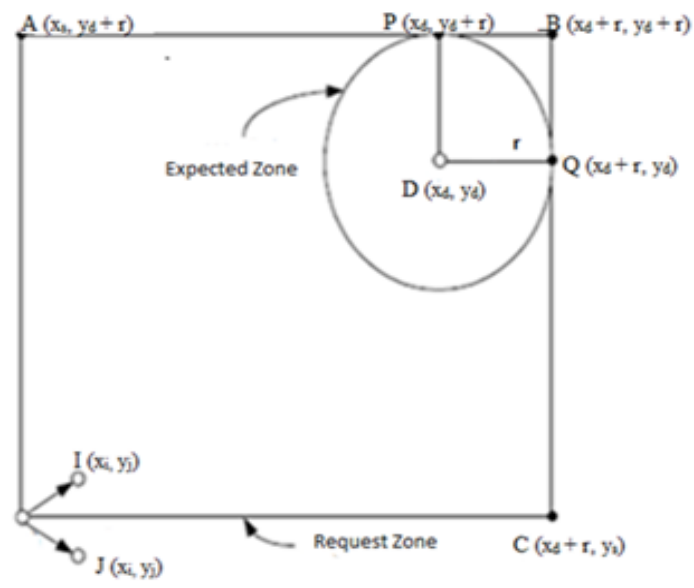

Fig 6. Location aided Routing Scheme

The source node is capable of determining the four corners of the rectangular request zone. This four coordinates are now included in the route request packet when initiating the route discovery process. Source node $\mathrm{S}$ sends a RREQ packets to its neighbour nodes. The nodes which are outside the rectangular area just drops the packet. When destination $\mathrm{D}$ receives the route request packet, it sends back a route reply packet as described in the flooding algorithms. Its reply differs by containing its current position, the actual time, and as an option its average speed. This information is used by source node for a route discovery in the future.

LAR Scheme 2 (LAR2) The second LAR scheme is defined by specifying (estimated) destination coordinates $\left(\mathrm{x}_{\mathrm{d}}, \mathrm{y}_{\mathrm{d}}\right)$ plus the distance to the destination [4]. The estimated destination and the current distance to it are included in the route request. Here, a node may only forward the route request packet if it is closer or at maximum _ farther away than the previous node. Every forwarding node overwrites the distance field in the packet with its own current distance to the destination. This process ensures that the packet moves towards the destination.

VII. COMPARISION

Table 1 Comparison Of Routing Protocols

\begin{tabular}{|l|l|l|l|l|l|}
\hline $\begin{array}{l}\text { S. } \\
\text { No }\end{array}$ & Properties & AODV & DSDV & DSR & LAR \\
\hline 1. & $\begin{array}{l}\text { Protocol } \\
\text { Type }\end{array}$ & Reactive & Proactive & Proactive & Reactive \\
\hline 2. & $\begin{array}{l}\text { Route } \\
\text { Discovery }\end{array}$ & $\begin{array}{l}\text { On } \\
\text { Demand }\end{array}$ & Periodic & $\begin{array}{l}\text { On } \\
\text { Demand }\end{array}$ & $\begin{array}{l}\text { On } \\
\text { Demand }\end{array}$ \\
\hline 3. & $\begin{array}{l}\text { Need of } \\
\text { Hello } \\
\text { message }\end{array}$ & YES & YES & NO & NO \\
\hline 4. & $\begin{array}{l}\text { Route } \\
\text { Maintenan } \\
\text { ce }\end{array}$ & $\begin{array}{l}\text { Route } \\
\text { table } \\
\text { with next } \\
\text { hop }\end{array}$ & $\begin{array}{l}\text { Route } \\
\text { table with } \\
\text { next hop }\end{array}$ & $\begin{array}{l}\text { Complete } \\
\text { Route } \\
\text { cached }\end{array}$ & $\begin{array}{l}\text { Complete } \\
\text { Route } \\
\text { cached }\end{array}$ \\
\hline 5. & $\begin{array}{l}\text { Multiple } \\
\text { Routes }\end{array}$ & No & No & YES & Yous \\
\hline 6. & Loop Free & YES & YES & YES & YES \\
\hline 7. & $\begin{array}{l}\text { Network } \\
\text { Overhead }\end{array}$ & Medium & High & Low & Medium \\
\hline 8. & $\begin{array}{l}\text { Multi-hop } \\
\text { Wireless } \\
\text { Support }\end{array}$ & YES & YES & YES & YES \\
\hline
\end{tabular}




\begin{tabular}{|c|c|c|c|c|c|}
\hline 9. & $\begin{array}{l}\text { Network } \\
\text { Suitable } \\
\text { for }\end{array}$ & $\begin{array}{l}\text { Highly } \\
\text { Dynamic }\end{array}$ & $\begin{array}{l}\text { Less } \\
\text { number } \\
\text { of nodes }\end{array}$ & $\begin{array}{l}\text { Up to } 200 \\
\text { nodes }\end{array}$ & $\begin{array}{l}\text { Highly } \\
\text { Dynamic }\end{array}$ \\
\hline 10. & $\begin{array}{l}\text { Multiple } \\
\text { Routes }\end{array}$ & $\mathrm{NO}$ & $\mathrm{NO}$ & YES & $\mathrm{NO}$ \\
\hline 11. & $\begin{array}{l}\text { Routing } \\
\text { metric }\end{array}$ & $\begin{array}{l}\text { Shortest } \\
\text { Path }\end{array}$ & $\begin{array}{l}\text { Shortest } \\
\text { Path }\end{array}$ & $\begin{array}{l}\text { Shortest } \\
\text { Path }\end{array}$ & $\begin{array}{l}\text { Shortest } \\
\text { Path }\end{array}$ \\
\hline 12. & $\begin{array}{l}\text { Routing } \\
\text { Overhead }\end{array}$ & HIGH & $\begin{array}{l}\text { MEDIU } \\
\text { M }\end{array}$ & LOW & LOW \\
\hline 13. & $\begin{array}{l}\text { ADVANT } \\
\text { AGES }\end{array}$ & $\begin{array}{l}\text { It is loop } \\
\text { free self } \\
\text { starting } \\
\text { and } \\
\text { scales to } \\
\text { large } \\
\text { numbers } \\
\text { of mobile } \\
\text { nodes }\end{array}$ & $\begin{array}{l}\text { DSDV } \\
\text { protocol } \\
\text { guarantee } \\
\text { s loop } \\
\text { free paths } \\
\text { and } \\
\text { Count to } \\
\text { infinity } \\
\text { problem } \\
\text { is } \\
\text { reduced } \\
\text { in DSDV. }\end{array}$ & $\begin{array}{l}\text { DSR uses } \\
\text { no periodic } \\
\text { routing } \\
\text { messages } \\
\text { like } \\
\text { AODV, } \\
\text { thereby } \\
\text { reduces } \\
\text { network } \\
\text { bandwidth } \\
\text { overhead, } \\
\text { conserves } \\
\text { battery } \\
\text { power and } \\
\text { avoids } \\
\text { large } \\
\text { routing } \\
\text { updates. }\end{array}$ & $\begin{array}{l}\text { It reduces } \\
\text { routing } \\
\text { overhead } \\
\text { of the ad- } \\
\text { Hoc } \\
\text { network by } \\
\text { using } \\
\text { location } \\
\text { informatio } \\
\text { n. } \\
\text { Complexit } \\
\text { y of } \\
\text { protocol is } \\
\text { reduced } \\
\text { assuming } \\
\text { that each } \\
\text { node } \\
\text { recognizes } \\
\text { position } \\
\text { accurately. }\end{array}$ \\
\hline 14. & $\begin{array}{l}\text { DISADVA } \\
\text { NTAGES }\end{array}$ & $\begin{array}{l}\text { Intermedi } \\
\text { ate nodes } \\
\text { can lead } \\
\text { to } \\
\text { inconsiste } \\
\text { nt routes } \\
\text { if the } \\
\text { source } \\
\text { sequence } \\
\text { number is } \\
\text { very old } \\
\text { and } \\
\text { intermedi } \\
\text { ate nodes } \\
\text { have the } \\
\text { higher } \\
\text { but not } \\
\text { the latest } \\
\text { destinatio } \\
\mathrm{n} \\
\text { sequence } \\
\text { number, } \\
\text { thereby } \\
\text { having } \\
\text { stale } \\
\text { entries }\end{array}$ & $\begin{array}{l}\text { DSDV } \\
\text { requires } \\
\text { regular } \\
\text { update of } \\
\text { its } \\
\text { routing } \\
\text { tables } \\
\text { which } \\
\text { uses up } \\
\text { battery } \\
\text { power. } \\
\text { DSDV is } \\
\text { not } \\
\text { suitable } \\
\text { for highly } \\
\text { dynamic } \\
\text { networks. }\end{array}$ & $\begin{array}{l}\text { Route } \\
\text { maintenan } \\
\text { ce } \\
\text { mechanis- } \\
\text { m does not } \\
\text { locally } \\
\text { repair a } \\
\text { broken } \\
\text { down link. } \\
\text { Considerab } \\
\text { le routing } \\
\text { overhead is } \\
\text { involved } \\
\text { due to } \\
\text { source } \\
\text { routing } \\
\text { mechanism } \\
\text { employed } \\
\text { in DSR }\end{array}$ & $\begin{array}{l}\text { Limitation } \\
\mathrm{s} \text { of this } \\
\text { protocol is } \\
\text { every host } \\
\text { requires a } \\
\text { GPS } \\
\text { device. }\end{array}$ \\
\hline
\end{tabular}

VIII.

CONCLUSION

In this paper we provide descriptions of several routing protocols proposed for ad Hoc mobile networks. We also classified these protocols according to the routing strategy (i.e., table-driven and on-demand). We have presented a comparison of these two categories of routing protocols, highlighting their features, differences, characteristics advantages and disadvantages. The field of ad Hoc mobile networks is rapidly growing and changing, and while there are still many challenges that need to be met, it is likely that such networks will see widespread use within the next few years.

\section{REFERENCES}

[1]. Basu Dev Shivahare, Charu Wahi, Shalini Shivhare, "Comparison Of Proactive And Reactive Routing Protocols In Mobile AdHoc Network Using Routing Protocol Property,” IJETAE, Volume 2, Issue 3, pp. 356-359, March 2012.

[2]. C. E. Perkins and P. Bhagwat, "Highly Dynamic Destination-Sequenced Distance-Vector Routing (DSDV) for Mobile Computers," SIGCOMM, Oct. 1994, pp. 234-44.

[3]. Davesh Singh Som, Dhananjaya Singh, "Performance Analysis and Simulation of AODV,DSR and TORA Routing Protocols in MANETs,” IJRTE, Volume-1, Issue-3, August 2012, pp 122-127. 
[4]. David Oliver Jörg, "Performance Comparison Of MANET Routing Protocols In Different Network Sizes," 2003.

[5]. Basu Dev Shivahare, Charu Wahi, Shalini Shivhare, "Comparison Of Proactive And Reactive Routing Protocols In Mobile AdHoc Network Using Routing Protocol Property,” IJETAE, Volume 2, Issue 3, pp. 356-359, March 2012.

[6]. C. E. Perkins and P. Bhagwat, "Highly Dynamic Destination-Sequenced Distance-Vector Routing (DSDV) for Mobile Computers," SIGCOMM, Oct. 1994, pp. 234-44.

[7]. Davesh Singh Som, Dhananjaya Singh, "Performance Analysis and Simulation of AODV,DSR and TORA Routing Protocols in MANETs," IJRTE, Volume-1, Issue-3, August 2012, pp 122-127.

[8]. David Oliver Jörg, "Performance Comparison Of MANET Routing Protocols In Different Network Sizes," 2003.

[9]. Sumaiya Thaseen and K Santhi, "Performance Analysis of FSR, LAR and ZRP Routing Protocols in MANET," International Journal of Computer Applications, vol. 41, issue 4, pp. 20-24, 2012.

[10]. Elizabeth M. Royer, "A Review of Current Routing Protocols for Ad Hoc Wireless Networks," Personal Communications, IEEE, vol. 6, issue: 2 , pp. $46-55$.

[11]. Young-Bae Ko and Nitin H. Vadiya, "Location-Aided Routing in mobile ad Hoc networks," Journal Wireless Networks, vol. 6, Issue 4, pp. 307-321, sept 2000.

[12]. A.A.A. Radwan, T.M. Mahmoud, E.H.Houssein, "Evaluation comparison of some ad Hoc networks routing protocols", Egyptian information Journal, vol. 12, Issue 2, July 2011, pp. 95-106, 2011.

[13]. Mohammad A. Mikki, "Energy Efficient Location Aided Routing Protocol for Wireless MANETs," IJCSIS, vol. 4, No. 1 \& 2, August 2009.

[14]. Rahul Desai, B P Patil, "A Survey of On Demand Routing Protocols for Mobile Ad Hoc Network," International Journal of Innovation, Management and Technology, IJIEASR, vol. 1, No. 2, pp 6-12, November 2012.

[15]. Priyanka Goyal, Vinti Parmar, Rahul Rishi "MANET: Vulnerabilities, Challenges, Attacks, Application," IJCEM, International Journal of Computational Engineering \& Management, vol. 11, pp. 32-37, January 2011.

[16]. Carlos de Morais Cordeiro and Dharma P. Agrawal, "Mobile Ad Hoc Networking," OBR Research Center for Distributed and Mobile Computing, ECECS, pp. 1-63, 2004.

[17]. Basu Dev Shivahare, Charu Wahi, Shalini Shivhare, "Comparison Of Proactive And Reactive Routing Protocols In Mobile AdHoc Network Using Routing Protocol Property,” IJETAE, Volume 2, Issue 3, pp. 356-359, March 2012.

[18]. P.T.V.Bhuvaneswari and V.Vaidehi, "Location Aided Energy Efficient Routing Protocol in Wireless Sensor Network," IJSSST, Vol. 11, No. 4, pp. 41-50, 2008.

[19]. Dr.S.S.Dhenakaran, A.Parvathavarthini, “An Overview of Routing Protocols in Mobile Ad-Hoc Network,” IJARCSS, Volume 3, Issue 2, pp. 251-259, February 2013.

[20]. Qi Xue , Aura Ganz. “Ad Hoc QoS on-demand routing (AQOR) in mobile ad Hoc networks", Journal of Parallel and Distributed Computing, vol. 63. Issue 2, pp. $154-165,2003$.

[21]. Hannan XIAO, Winston K.G. SEAH, Anthony LO and Kee Chiang CHUA "A Flexible Quality Service Model for Ad-HOC Networks," IEEE, vol., pp. 445-449, May 2000.

[22]. Y. Ko and N. H. Vaidya "Location-aided routing (LAR) in mobile ad Hoc networks," Journal Wireless Networks," Vol.6, No. 4, pp. 307-321, July 2000.

[23]. Nen-Chung Wang, Si-Ming Wang, "An Efficient Location-Aided Routing Protocol for Mobile Ad Hoc Networks," 11th International Conference, vol. 1, pp. 335-341, 2005.

[24]. Tzay-Farn Shih, Hsu-Chun Yen, "Location-aware routing protocol with dynamic adaptation of request zone for mobile ad Hoc networks", Journal, vol. 14, Issue 3, pp. 321-333, June 2008.

[25]. Martin Mauve and Jörg Widmer, "A Survey on Position-Based Routing in Mobile Ad Hoc Networks", IEEE (Volume: 15, Issue: 6, pp. 31-39.

[26]. Sidi-Mohammed Senouci and Tinku Mohamed Rasheed, "Modified Location-Aided Routing Protocols for Control Overhead Reduction in Mobile Ad Hoc Networks", FIP — The International Federation for Information Processing, Volume 229, pp 137-146, 2007.

[27]. T. Camp, J. Boleng, B. Williams, L. Wilcox, and W. Navidi, "Performance comparision of two location- based routing protocols for ad Hoc networks," in Proc. IEEE INFOCOM, Vol:3, pp. 1678-1687, 2002.

[28]. B. Karp, and H. T. Kung, "GPSR: Greedy perimeter stateless routing forwireless networks" in Proc. IEEE/ACM MOBICOM, Boston, MA. pp. 243-254, Aug.2000.

[29]. W. KieS, H. FuSler, and J. Widmer, "Hierarchical location service for mobile ad Hoc networks" in Proc. ACM SIGMOBILE, vol. 8 , no. 4, pp. 47-58, Oct.2004

[30]. Sumaiya Thaseen and K Santhi, "Performance Analysis of FSR, LAR and ZRP Routing Protocols in MANET," International Journal of Computer Applications, vol. 41, issue 4, pp. 20-24, 2012.

[31]. Elizabeth M. Royer, "A Review of Current Routing Protocols for Ad Hoc Wireless Networks," Personal Communications, IEEE, vol. 6 , issue: 2 , pp. $46-55$.

[32]. Young-Bae Ko and Nitin H. Vadiya, "Location-Aided Routing in mobile ad Hoc networks," Journal Wireless Networks, vol. 6, Issue 4, pp. 307-321, sept 2000. 